Talía. Revista de estudios teatrales

ISSN-e 2659-806X

\title{
Miguel F. Gil Palacios (ed.), Generación Romero Esteo, Recherches. Culture et histoire dans l'espace roman, 22. Estrasburgo: Universidad de Estrasburgo, 2019. ISSN: 1968035X. 196 pp.
}

María Serrano Aguilar*

El monográfico de la revista Recherches de la Universidad de Estrasburgo aporta un acercamiento crítico a esta generación de autores andaluces que están comenzando a atraer el foco de atención sobre su producción dramática. Todos ellos nacieron entre 1968 y 1985 y tomaron contacto a través del concurso que lleva el nombre del dramaturgo Miguel Romero Esteo, quien reconoció la importancia de este premio para editar y representar a los nuevos autores. Como indica $\mathrm{M}^{\mathrm{a}}$ Jesús Bajo Martínez a modo de introducción, estos creadores nacen entre años cercanos, poseen una educación similar y mantienen relación entre ellos. Algunos manifiestan esta relación en creaciones colectivas o colaboraciones, como Puertas Cerradas de Gracia Morales, Juan Alberto Salvatierra y Antonio Hernández Centeno, o los montajes de Javier Berger de textos de Miguel Palacios.

Pero, además, tienen en común presentarse al concurso, ganarlo o haber sido finalistas del mismo. Esto les permitió acceder a cursos impartidos por grandes dramaturgos como Sanchis Sinisterra, David Greig, Rodrigo García o Sara Kane. Por ello, presentan cohesión y coherencia como grupo en cuanto a sus influencias dramatúrgicas: todos utilizan un lenguaje actual y poco retórico, así como una escritura fragmentada que altera a veces la línea temporal. Es frecuente la utilización del humor y la ironía, además de la influencia del cine en sus guiones o la plasmación de un mundo fantástico que se aleja de la realidad.

Los análisis recogidos en la revista justifican la necesidad de investigar la creación de estos autores casi desconocidos desde diferentes enfoques. Algunos trabajan obras específicas dentro de la producción de alguno de ellos. Raquel Jurado Díaz, por ejemplo, ahonda en el texto Silencio de Sergio Rubio y establece un paralelismo con los trabajos musicales del compositor John Cage, apuntando que verdaderamente son los "silencios" dentro de la obra lo que plantean el conflicto principal en una relación de pareja donde la incomunicación construye la verdadera tensión. Los monólogos en voz alta, que no son escuchados por el otro personaje, constituyen el verdadero material dramático, mientras que las intervenciones "sonoras", es decir, con intención comunicativa entre los personajes, no tienen más contenido que resaltar la incomunicación que hay entre ambos.

$\mathrm{M}^{\mathrm{a}}$ del Carmen Rodríguez Álvarez cambia el foco respecto a los demás análisis del monográfico, centrados principalmente en los textos, y analiza la puesta en escena de El Rey de Algeciras de Juan Alberto Salvatierra. La obra, estrenada en 2003 en el Teatro Central de Sevilla y producida por el CAT, plasma la situación social y política de Algeciras en una obra estructurada en "mosaico": presenta los hechos de manera fragmentaria y no organizada en el tiempo dramático tradicional. Se presentan personajes marginados, que rompen con la moral imperante y que hablan con un lenguaje directo y preciso que a veces ralla lo escatológico, pero solo como justificación y matiz de un argumento agrio que no busca comicidad ni facilitar al público la digestión de los hechos que se presentan en escena.

La figura de la mujer en su entorno social es el tema central del análisis de Eva Romero-Molina sobre las obras Cuando regreses a Nueva York y Amina de Carmen Pombero. Destaca en ambas creaciones un cariz determinista, siendo más compatibilista y abierto en la primera obra y descarnado e inexorable en la segunda. No obstante, en ambos casos la dramaturga muestra preocupación por la situación de la mujer en nuestra sociedad actual, abordada desde diferentes contextos sociopolíticos. En Amina, trata un delicado tema basado en un acontecimiento real, donde el suicidio acaba convirtiéndose en la única salida posible para un personaje aplastado por su entorno social.

El último estudio centrado en el análisis de una obra es el de Juan Antonio Bernal Tena, quien expone la labor creativa de Javier Berger en Franco, el retorno. Se nos presenta al autor que abrió la generación Miguel Romero Esteo con Doctor, ¿es cierto que el hombre está compuesto de un $70 \%$ de agua? Franco, el retorno fue estrenada el 11 de febrero de 2010 y no tuvo la repercusión que se esperaba. Se trata de una obra ácida, protagonizada por dos ancianos llamados Paco y Carmen con cuyas figuras se juega a la indeterminación: podrían ser Francisco Franco y Carmen Polo o podrían ser solo dos ancianos franquistas y melancólicos que juegan al disfraz. La utilización de títeres para el juego de identi- 
dades en la escena acentúa esta impresión de indeterminación en los roles, y los momentos de karaoke rescatan el carácter musical del texto original.

Otros trabajos del monográfico muestran una panorámica sobre un autor concreto dentro de la generación. Para la de Marilia Samper, Eduardo Chivite Tortosa recorre tanto la actividad dramatúrgica de la autora como sus labores de directora o sus acercamientos al teatro radiofónico (Líneas), al musical (Paradis) y a las creaciones colectivas (Animales de companya). Se hace especial hincapié en la capacidad de la dramaturga para construir su poética a partir de los deseos realizados de sus personajes. Sus conflictos nacen del imaginario y no de la acción que sucede, como en 405, o del imaginario que no solo se vuelve real, sino que va más lejos, hasta pervertirse, como sucede en Menú del día. Quedan expuestas en este recorrido la versatilidad de la creadora y sus diversas capacidades respecto al hecho teatral tanto en el texto como en la escena.

El recorrido creativo del también director de escena Antonio Hernández Centeno, es puesto de relieve por Miguel Ángel García, señalando su labor de director como un elemento imprescindible en sus obras, que no suelen acabar siendo representadas como originalmente fueron escritas. Aunque utiliza el humor y la ironía en muchos casos para no causar rechazo en el espectador, lo cierto es que los hechos, a veces terribles, son asimilados por el espectador sin saber si reír o llorar. Se destaca el juego entre la máscara y la contramáscara: la mayoría de los personajes viven cargados de mentiras, engaños y falsas apariencias, que se articulan mediante una sinergia de diálogos entrecruzados en los que los personajes parecen responderse. Entre sus temas más habituales se encuentra la homosexualidad -hostigada por una intensa homofobia (Cinco; Fin; Bagdad, Madrid, New York. A.M; El gol de Alex) o como característica natural de sus personajes (Héroes, Buscando respuestas) -, el acoso escolar y el abuso a menores (Náufragos), la violencia machista (Cinco, El día en que te conoci) y el terrorismo (Héroes).

El análisis de uno de los más interesantes creadores de esta generación lo lleva a cabo Carmen Arribas Castillo en su estructuración tripartita de las etapas creativas de Miguel Palacios. En una primera etapa enmarcaría sus primeras obras - El tren (metamorphosis/curso intensivo de supervivencia), Los caballos no comen chocolate - fuertemente influida por el cine y las artes plásticas; en la segunda califica sus creaciones como tragedias delirantes, asociadas en su estilo a las grotescomaquias del Miguel Romero Esteo, a quien Palacios conoció y cuya visión del mundo reconoce haberle influido. Durante esta segunda etapa sus obras presentan un acentuado barroquismo y acusan la influencia de Góngora en su lenguaje, presentando a los personajes-muñeco de forma grotesca. Una tercera y última etapa estaría dedicada a un teatro más propiamente posdramático (Agamenón 09, La Pecera), con presencia de la fragmentación y la simultaneidad, con tendencia a establecer el conflicto con el espectador e invitarle a cuestionarse cuál es la realidad. Palacios demuestra gran versatilidad como creador, pues no deja de atreverse con diversos tipos de teatro como el ritual, inspirado por Artaud o Ghelderode (Los pequeños rituales, El viento norte en el laberinto de las puertas) o con nuevas formas de creación dentro del género del performance, como la serie $\mathrm{PH}$, pequeñas ceremonias que se desarrollan marcados por el azar y una compleja dramaturgia en espacios poco convencionales. Estamos ante un autor novedoso y creativo tanto en su forma como en contenido social y metafísico.

Finalmente, Carlos Alonso Callero nos acerca a la obra de otro autor polifacético en sus competencias, Tomás Afán Muñoz. Este autor ha compaginado la interpretación, la dirección, la producción, la gestión, e incluso la utilería, con la escritura teatral. Su dramaturgia se caracteriza por no ser apriorística y por jugar en cada paso del proceso creativo. Se desenvuelve con soltura en la estructura de pequeñas escenas unidas por un hilo conductor, manifestando un elocuente uso de la fragmentariedad en escena (Parejas) y un interés por la figura del Clown (Pim pam clown). Al escribir para adultos, no renunciará al tema de la infancia, aunque también sentirá interés por la recreación de mitos y los estereotipos de esquemas de géneros dramáticos y épicos, aunque siempre con el afán de juego que le lleva a subvertir los engranajes. Este prolífico autor de la generación Romero Esteo también se aventurará con el monólogo metafórico y laberíntico, sin renunciar a la claridad escénica con la que Alonso Callero le caracteriza.

Aunque en la nómina final de Miguel Palacios aparecen nombres que no han sido recogidos en los trabajos que constituyen el volumen, la muestra ofrece una visión clara de la novedad y la frescura de los integrantes de esta generación, además de poner de relieve el injusto desconocimiento que de ellos se tiene. Este último recuento de Miguel Palacios recoge un conciso acercamiento a las obras publicadas en el mismo volumen, todas ellas obras de los creadores a los que nos han acercado los análisis del monográfico.

Como se indica en la entrevista a Emilio Hernández recogida casi al comienzo del volumen, el premio Miguel Romero Esteo constituía un elemento clave para difundir la obra de estos dramaturgos concediendo como premio final la representación de la obra por parte del Centro Andaluz de Teatro. Tras dejar Emilio Hernández su puesto como director del mismo, la convocatoria del premio fue progresivamente disminuyendo, así como su recompensa: de representación en un teatro quedó en lectura dramatizada. Si la obra de teatro se efectúa y se colma en su representación, no podemos sino percibir como una gran pérdida para la escena (no solo la andaluza, sino también la española) la desaparición progresiva de este premio en un ya muy difícil escenario para el teatro dentro de la oferta cultural de España. El presente número de Recherches editado por Miguel Palacios constituye una pieza fundamental para el acercamiento a la actividad creativa de este grupo de autores andaluces, quienes, además de luchar por un hueco en la escena española, consiguieron establecer un ambiente creativo altamente constructivo y rico entre ellos. 